\title{
Anatomically corrected malposition of great arteries
}

\author{
Robert H. Anderson, Anton E. Becker, 'Tom G. Losekoot, and Leon M. Gerlis \\ From the Department of Paediatrics, Cardiothoracic Institute, Brompton Hospital, London; Departments of \\ Pathology and Paediatrics, University of Amsterdam, The Netherlands; and the Department of Pathology, \\ Grimsby General Hospital
}

Four anomalous hearts are described in which the great arteries arise in unusual fashion from their morphologically appropriate ventricles. This malformation, previously termed anatomically corrected transposition, is now termed anatomically corrected malposition. This is because, following the precedent of Van Praagh and his associates, we now reserve the term 'transposition' to describe the situation in which both great arteries arise from separate morphologically inappropriate ventricles. All the hearts examined exhibited atrioventricular concordance, $I$ with viscero-atrial situs inversus, and 3 with situs solitus. However, there were considerable variations in ventricular morphology between the cases. Thus, 2 cases exhibited atresia of the right atrioventricular valve, and in the remaining 2 cases right and left ventricular sinuses were both identified. Two of the cases also had pulmonary atresia, and coronary artery anomalies were present in all 4. The cases emphasize the fact that the term anatomically corrected malposition describes not a discrete anomaly but only a ventriculo-arterial relation, which is one of ventriculo-arterial concordance. Doubt has previously been cast upon the existence of this as an anatomical entity. It is concluded that the relation does indeed exist, and furthermore can coexist with all varieties of atrioventricular relations. It is suggested that the differing atrioventricular relations can be distinguished by usage of the terms 'concordant' or 'discordant' anatomically corrected malposition. Finally, it is emphasized that it is necessary to distinguish this anomaly, which in most cases presents with left-sided anterior aorta, from the left-sided anterior aorta more frequently encountered in 'classically corrected transposition'.

In recent years it has become evident that the term 'transposition' is used to describe a great variety of relations of the great arteries, and hence has become a non-specific term. This lack of specificity was highlighted by Van Praagh and his colleagues (197I) who suggested that it would be better if the term were used as initially intended (Farre, 1814), to describe the situation in which both great arteries were placed across the ventricular septum so as to arise independently from morphologically inappropriate ventricles (Fig. IB and C). They further indicated that it was necessary to introduce an additional term to describe arteries which were then neither transposed nor normally related. They therefore introduced the term malposition. This term itself was subdivided into malpositions in which only one artery is placed across the septum

Received 7 April 1975.

${ }^{1}$ R.H.A. was a MRC Travelling Fellow at the University of Amsterdam during the time of this investigation. He is now a British Heart Foundation Senior Research Fellow. Present address: Cardiothoracic Institute, London. so that both arteries then arise from the same ventricle, be it left or right (double outlet situations, Fig. ID and E), and the situation in which both arteries are abnormally related to their appropriate ventricles. The latter variety was termed 'anatomically corrected malposition' (Fig. IF).

This form of ventriculo-arterial relation had been previously referred to as anatomically corrected transposition (Harris and Farber, 1939). Some authorities (Van Mierop and Wiglesworth, 1963) had doubted the existence of the malformation on embryological premises, despite the fact that it had been described by distinguished morphologists such as Rokitansky (1875), Lewis and Abbott (I915), Carns, Ritchie, and Musser (I94I), and Doerr (1939). Van Praagh and Van Praagh (1967) indicated that they too had doubted its pedigree before studying three specimens which provided incontrovertible proof of its existence. Raghib, Anderson, and Edwards (1966) had described an example at much the same time, but had termed it 'isolated bulbar inversion'. Since then 


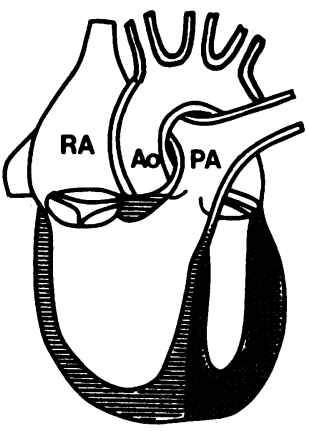

A. Normal heart

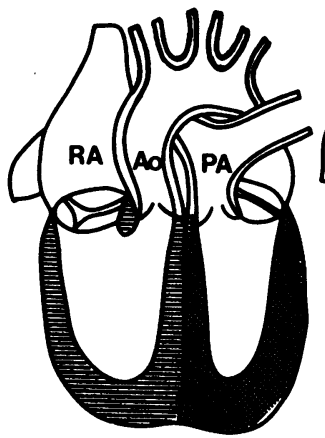

B. Completetransposition

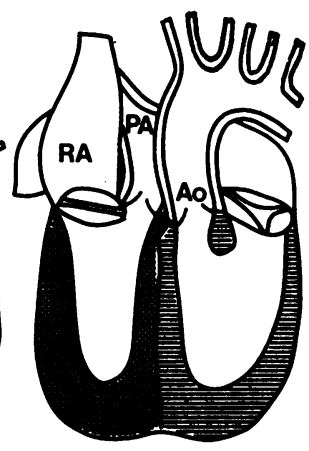

C. Corrected transposition

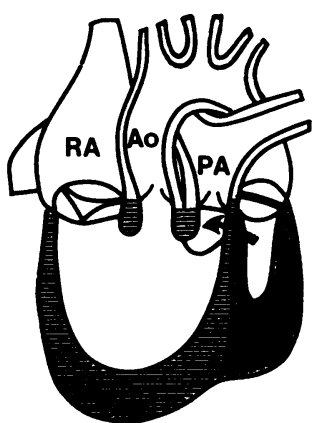

D. DORV with d-malposition

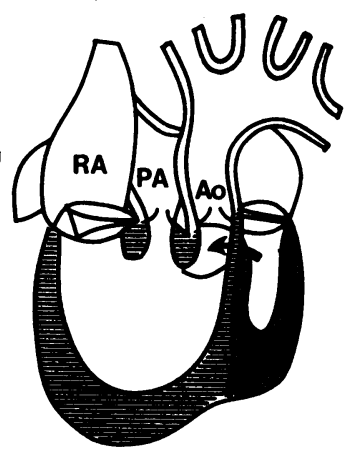

E. DORV with L-malposition

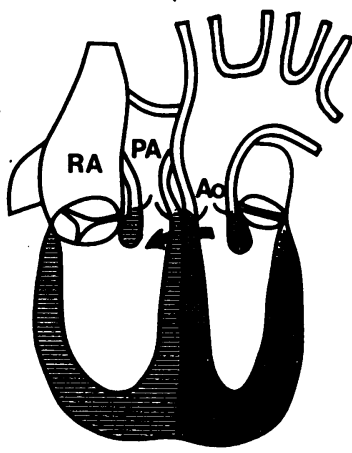

F. Anatomically corrected malposition

FIG. I Diagrams which illustrate the concept of transposition and malposition as espoused by Van Praagh and his colleagues (197I). Fig. IA shows the normal relation of the great arteries. The aorta is to the right of, and posterior to, the pulmonary artery. Fig. $I B$ and $C$ are both transpositions. The arteries are placed across the septum so as to arise from inappropriate ventricles. When associated with atrioventricular concordance $(I B)$ the circulation is transposed (complete transposition). When associated with atrioventricular discordance (IC) the circulation is corrected (corrected transposition). Fig. ID-F show malpositions. Fig. ID and $I E$ represent double outlet ventricle situations in which only one great artery (in the case of the right ventricle, the aorta; in the case of the left ventricle, the pulmonary artery) is placed across the septum. Double outlet right ventricle is illustrated. In this situation the aorta can be either to the right of the pulmonary artery (d-malposition) or to its left (l-malposition). Fig. IF shows the situation in which both arteries arise from appropriate ventricles, but are abnormally related. The aorta is to the left of, and in approximately the same frontal plane as, the pulmonary artery. In this report we have adopted the nomenclature of Van Praagh et al. (197I) and referred to this anomaly as 'anatomically corrected malposition'.

further descriptions have attested to the existence of this type of ventriculo-arterial relation (Anderson, Arnold, and Jones, 1972; Freedom and Harrington, 1974) while others have described repair of its associated cardiac defects (Sunada et al., 1967; Kirklin et al., r973).

However, while these reports attest to the existence of the malformation, they contribute further to the disagreements which surround it. Thus Kirklin et al. (1973) defined 'anatomically corrected malposition' when observed in association with atrioventricular concordance as a particular variety of ventriculo-arterial concordance, yet defined the same ventriculo-arterial relation as 'isolated ventricular inversion' when it was associated with discordant atria and ventricles. Furthermore, though Kirklin et al. (1973) have defined anatomically corrected malposition as a concordant relation between ventricles and arteries because pulmonary venous blood reaches the aorta, de la Cruz et al. (1974) define the same flow situation as a discordant arterio-ventricular relation if the pulmonary artery 
does not 'point' to the morphological right ventricle. A similar contrast is found concerning nomenclature of an anterior, left-sided aorta which arises from the left ventricle in some cases of tricuspid atresia with situs solitus. Freedom and Harrington (1974) referred to this arrangement as another example of anatomically corrected malposition. Tandon and Edwards (1974) on the other hand described the arteries when thus arranged as exhibiting $l$-transposition. The latter usage is particularly confusing since the term 'tricuspid atresia with l-transposition' is also used to describe the anomaly in which atresia of the left-sided atrioventricular valve occurs in hearts with solitus atrial chambers, atrioventricular discordance, and $l$-transposition (classically corrected transposition).

It is, therefore, evident that, though several investigators have already adopted the terminology of Van Praagh et al. (197I), usage of the term 'anatomically corrected malposition' is by no means generally accepted or agreed upon. For this reason we are now describing an additional 4 examples of the malformation. Though the hearts exhibit considerable variations in the morphology of their atrial and ventricular chambers, they all have the same ventriculo-arterial relation. We will indicate why we believe the term 'anatomically corrected malposition' provides the best description of this relation. We will then indicate how the term can be used in conjunction with descriptions of atrioventricular relations and anomalies. Finally, we will demonstrate how, when interpreted in the setting of the conal maldevelopment hypothesis, this ventriculo-arterial relation should no longer be considered an embryological impossibility.

\section{Definition of terms}

As we have indicated in the introduction, we shall employ the definition of Van Praagh et al. (197I) for transposed and malposed great arteries. In all situations, unless stated otherwise, we shall refer to the relative positions of the aorta and pulmonary artery at their valve rings, and will describe these simply as 'aorta' and 'pulmonary artery'.

Transposition of the great arteries will, therefore, describe only that situation in which the aorta arises from the morphologically right ventricle and the pulmonary artery from the morphologically left ventricle (Fig. 2B).

Malposition of the great arteries will describe two situations. Firstly, that in which both arteries arise from the same ventricle, be it right or left ventricle (Fig. $\mathrm{ID}, \mathrm{E}$ ). When the aorta in this situation is to the right, it will be described as being $d$-malposed with relation to the pulmonary artery; similarly when the aorta is to the left, it will be described as being $l$-malposed. The second category of malposition will describe the anomaly in which both great arteries arise from their appropriate ventricles (or their embryological anlagen) but in which either one or both arteries are abnormally related to their ventricles. This category will be termed 'anatomically corrected malposition' (Fig. IF). Arteries arising in normal fashion from their appropriate ventricles will be described as being normally related. This arrangement of great arteries for a $d$-bulboventricular loop is for the aorta, though arising from the morphological left ventricle, to be posterior and right-sided with relation to the pulmonary artery, and for the adjoining portions of its non-coronary and left coronary cusps to be in fibrous continuity with the mitral valve (Fig. 2A). In an $l$-bulboventricular loop, the normally related aorta, arising from the right-sided morphologically left ventricle would be left-sided and posterior, with fibrous continuity between the right-sided mitral valve and the adjoining portions of the right and non-coronary aortic cusps (Fig. 2D). It, therefore, follows that the situation in which a left-sided aorta arose from a left-sided morphological left ventricle would be considered as anatomically corrected malposition irrespective of the presence or absence of mitral-aortic valvar continuity. Similarly, if in the presence of an l-loop the aorta was right-sided and in fibrous continuity with the rightsided mitral valve, this would be described as anatomically corrected malposition. We are aware that Van Praagh and Van Praagh (1966) have described such a situation as a variant of normal, or 'isolated ventricular inversion'. As we shall indicate subsequently, we do not consider this justified because the great arteries are not normally related to their appropriate ventricles, but are malposed. The definition of 'anatomically corrected malposition' presently employed is, therefore, that situation in which both great arteries arise from their appropriate ventricles but in which either is abnormally related to its ventricle.

\section{Chamber designation}

We shall refer to the cardiac chambers in terms of their morphological characteristics irrespective of their positions relative to the right and left sides of the body (Lev and Rowlatt, 196r). Thus the morphologically right atrium will refer to the chamber with the anatomical characteristics of the normal systemic venous atrium, and the morphologically right and left ventricles will refer to the normal venous and arterial ventricles, respectively. However, wherever a chamber does not correspond to 


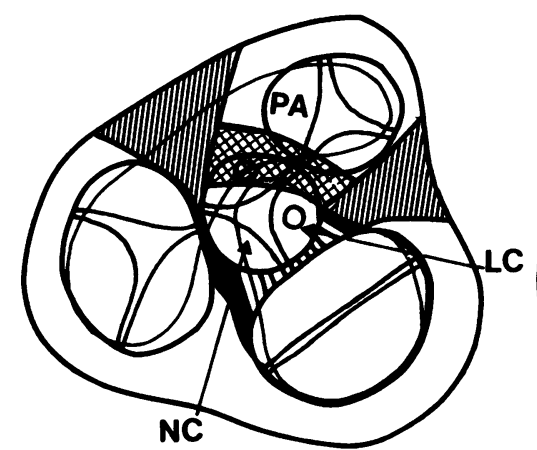

A. Normally related

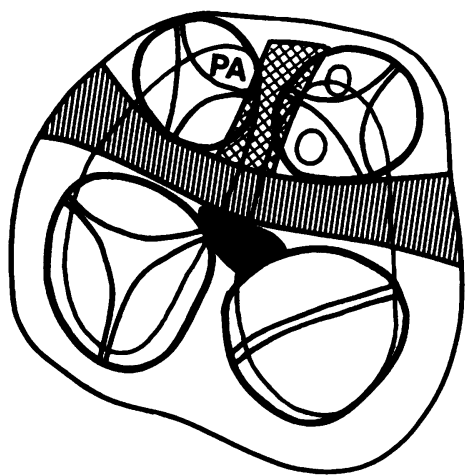

C. Malposition Right

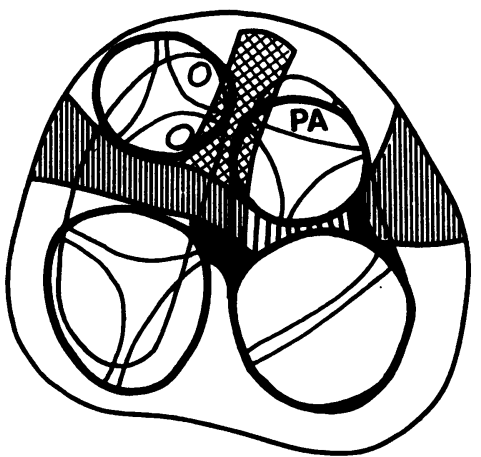

B. Transposition

FIG. 2 Diagrams illustrating in greater detail the relation of the arteries to the underlying ventricles in $A$ ) and $D$ ) normal hearts, $B$ ) transposition, and $C$ ) anatomically corrected malposition. In the normal heart, following absorption of the conoventricular flange, the aorta is transferred to the left ventricle. Aortic-mitral valvular continuity is present between the mitral valve and the adjacent parts of the non-coronary $(N C)$ and left coronary $(L C)$ cusps of the aortic valve. The aorta is posterior to and to the right of the pulmonary artery. In the mirror image normal heart (Fig. $2 D$ ) the relations are reversed with respect to the right-left axis. Thus the aorta is to the left of and posterior to the pulmonary artery, and continuity is made between the adjacent parts of the right coronary $(R C)$ and non-coronary cusps and the mitral valve. The relation should be considered as the normal relation with regard to an l-bulboventricular loop irrespective of the atrial situs. Fig. $2 B$ shows the usual relation in complete transposition (see Fig. I). The aorta is placed across the septum to arise anteriorly from its inappropriate ventricle, the right. The pulmonary artery arises posteriorly from the left ventricle, and pulmonary-mitral valvular continuity is usually present. Fig. $2 \mathrm{C}$ represents the usual arrangement in 'anatomically corrected malposition' with solitus atria and atrioventricular concordance. The great arteries arise from their appropriate ventricles, but are in approximately the same frontal plane. Neither semilunar valve is usually in fibrous contact with an atrioventricular valve (bilateral conus). The aorta is to the left of the pulmonary artery. 
its usual position, we shall continue to adopt the precedent of Lev and Rowlatt (196I) and refer also to its position; thus we would describe a 'morphologically right atrium (left-sided)', when this chamber is in inverted position.

Conus septum will be used to describe the muscular septum which separates that part of the ventricular outflow tracts derived from the embryonic bulbus (Anderson et al., 1974c).

Conoventricular flange will be used to describe the muscular tissue intervening in the specimens described between the semilunar and the atrioventricular valves. It represents the inner curvature of the primitive heart tube and can also be considered as conal musculature. We have previously referred to this structure in embryological terms as the bulboatrioventricular ledge (Anderson et al., 1974c, d). When it is absorbed then semilunar-atrioventricular valvular fibrous continuity occurs.

\section{Description of specimens}

\section{Case I}

This heart was from a male infant who died at the age of 4 months. Only the heart and lungs were available for examination but the hospital records indicated that a spleen had been observed at necropsy. Though both lungs were bilobed, and no eparterial bronchus could be identified, the atrial chambers were arranged as for the situs solitus visceral arrangement. Thus the right-sided atrium received a small right superior vena cava and a large dilated left superior vena cava which drained to the atrium via a coronary sinus. The chamber also received the inferior vena cava and was in communication with the left atrium via a secundum type of atrial septal defect (Fig. 3B). There was partial juxtaposition of the right auricle. A blunt pouch extended to the right and a longer appendage passed posterior to the great arteries to lie alongside the left auricle (Fig. 3A). This auricle was more reminiscent of the normal left auricle than that normally arising from the right atrium. The leftsided atrium received 4 pulmonary veins and gave rise to a typical left auricle. Atrioventricular concordance was present. Thus the right atrium drained to the morphologically right ventricle (right-sided) via a valve with the characteristics of the tricuspid valve. However, the sinus of this ventricle was small and muscle bound, containing multiple posterior papillary muscles (Fig. 3C). The left atrium opened to the left ventricle through a mitral valve, and the sinus of this ventricle was well formed (Fig. 3D). The great arteries arose from the ventricles in a side-by-side position, with the pulmonary artery to the right of the aorta (Fig. 3A). Both arteries were separated from the atrioventricular valves by large segments of conoventricular flange, so that a bilateral conus was present (Fig. $3 \mathrm{C}$ and D). The two conuses were in continuity through a large anterior ventricular septal defect. The tricuspid and mitral valves were in continuity in the posterior edge of this defect (Fig. ${ }_{3} \mathrm{C}$ and D). The roof of the defect was formed by a prominent conus septum, while its floor was the anterior ventricular septum (Fig. 3D). The anterior portion of the right-sided ventricle was coarsely trabeculated and contained a well-formed trabecula septomarginalis on its septal aspect. The latter structure gave rise inferiorly to the anterior papillary muscle of the tricuspid valve and superiorly to the conal papillary muscle (Fig. ${ }_{3} \mathrm{C}$ ). Such structures were lacking from the anterior portion of the left-sided ventricle and the septal aspect of this ventricle was smooth (Fig. 3D). However, a prominent trabecula was present posteriorly in the left ventricle. A large coronary artery arose from the right septal aortic sinus which gave rise to right, left circumflex, and anterior descending coronary arteries. A very small coronary artery arose from the left septal aortic sinus and passed into the atrioventricular groove. The aortic arch was right-sided and a right-sided persistent ductus arteriosus was identified.

The diagnosis of anatomically corrected malposition with atrioventricular concordance $\{S, D, L\}$ was made. Though the atria were identified in the solitus arrangement, the position of the auricular appendages and the presence of two lungs with characteristics of left lungs presented the possibility that the case may have been associated with the polysplenia syndrome. However, the hospital records had indicated that the abdominal organs were normally arranged. The malformation was additionally complicated by the presence of a secundum atrial septal defect, a ventricular septal defect, hypoplasia of the right ventricular sinus, a right-sided aortic arch with persistent right-sided ductus arteriosus and coronary artery abnormalities.

\section{Case 2}

The specimen was from a male neonate dying at the age of 3 days. At necropsy, the thoraco-abdominal organs were found to be arranged as in situs inversus totalis. The spleen was identified on the right side, and was single. Other findings were confined to the heart, which was situated in the left hemithorax (laevocardia with situs inversus). The atrial chambers were inverted. The right-sided left atrium received 4 pulmonary veins, and possessed a typical left auricle (Fig. $4 \mathrm{~B}$ ). The morphologically right atrium (left-sided) received a left superior vena cava, inferior vena cava, and a small coronary sinus. Its auricle was typical of the morphologically right atrium. The two atria were in communication through a secundum type of atrial septal defect which was partially guarded by a filigreed septum primum (Fig. 4C). The right-sided left atrium drained to the morphologically left ventricle (right-sided) (Fig. 4C). The ventricle contained a typical mitral valve with two prominent papillary muscles in anterior and posterior positions. The surface of the ventricular septum was smooth in this ventricle. The left-sided right atrium drained to the morphologically right ventricle (left-sided) and its orifice was guarded by a morphologically tricuspid valve (Fig. 5). Multiple posterior papillary muscles 
were present together with a large anterior papillary muscle which took origin from a well-formed left-sided infundibulum, and the conal papillary muscle arose from this structure (Fig. 5). The aorta and pulmonary artery arose in the same frontal plane, but the pulmonary artery was atretic (Fig. 4A). When observed from the ventricular aspect, the aorta straddled a large anterior septal defect, and was separated from the right-sided mitral valve by the prominent conoventricular flange (Fig. $4 \mathrm{C}$ ). It was judged that the greater part of the aorta arose from the left ventricle (right-sided). Though the pulmonary artery was atretic, its conal origin could be identified. This slit-like structure was separated from the aortic orifice by the conus septum and from the tricuspid valve ring (left-sided) by the left extremity of the conoventricular flange. The septal defect was straddled superiorly by the aortic valve ring. Its floor was the anterior portion of the ventricular septum, and the atrioventricular valve rings were fused in the posterior aspect. The aorta ascended to the right of the pulmonary artery (Fig. 4A) and the aortic arch was rightsided. The pulmonary arteries were filled via a rightsided persistent ductus arteriosus. A single coronary artery was present arising from the right septal aortic sinus which gave rise to the right circumflex, left, and anterior descending coronary arteries.

The diagnosis was made of anatomically corrected malposition in situs inversus with atrioventricular concordance $\{\mathrm{I}, \mathrm{L}, \mathrm{D}\}$. Additional malformations were secundum atrial septal defect, pulmonary atresia, ventricular septal defect, hypoplasia of the sinus of the morphologically right ventricle, persistent ductus arteriosus, and single coronary artery.

Case 3

A male infant died at the age of $5 \frac{1}{2}$ months. The viscera were arranged in solitus fashion. The atrial chambers were concordant with visceral situs, but the right atrium possessed no outlet other than through a secundum type of atrial septal defect (Fig. 6B). The septum primum was herniated into the left atrium (Fig. 6C). The superior and inferior caval veins drained into the right atrium. A coronary sinus was not identified, neither was there any evidence of a 'dimple' on the floor of the chamber (Fig. 6B). The left atrium was enlarged and received pulmonary blood via normal pulmonary veins, and right atrial blood through the foramen ovale. A mitral valve guarded the orifice from the left atrium to a 'single' ventricular chamber (Fig. 6C). The valve possessed cusps typical of the mitral valve, and the posterior papillary muscle was of mitral pattern. The large anterior papillary muscle arose from the ventricular wall, and in addition from a large trabecula which extended from the ventricular apex to the underside of the conus septum (Fig. 6D). The great arteries arose anteriorly from the 'single' ventricular chamber, and the trabecula produced some separation between the two outflow tracts. The aorta was to the left of the pulmonary artery (Fig. 6A). The pulmonary artery was small, and its outflow tract was stenosed. Both semilunar valves were separated from the mitral valve by a persistent conoventricular flange (Fig. 6D). There was additional dome-shaped stenosis of the pulmonary valve. There was no evidence of either right or left bulboventricular ridges within the 'single' ventricular chamber. The aortic arch was left-sided, and the ductus arteriosus was patent. A single coronary artery arose from the right septal aortic sinus (Fig. 6A) and gave rise to a right circumflex, a right marginal, and left circumflex branches. The latter branch ran to the left, posteriorly to the great arteries.

The diagnosis was made of tricuspid atresia with single ventricle. The 'single' ventricle was considered to represent an unseptated bulboventricular loop, with

FIG. 3 Photographs illustrating the pertinent features of Case I. Fig. $3 A$ shows the anterior view of the heart. The aorta $(A o)$ is to the left of the pulmonary artery $(P A)$. Both great arteries are deviated rightwards, and there is partial juxtaposition of the atrial appendages $(R A A, L A A)$. The large persistent left superior vena cava is seen (LSVC). Fig. $3 B$ shows the right-sided chambers of the heart. A typical right atrium receiving the right superior vena cava $(R S V C)$, left superior vena cava via the coronary sinus (CS), and the inferior vena caua, drains through a morphologically tricuspid valve (TV) to the morphologically right ventricle. The opening of the juxtaposed portion of the auricle $(R A A)$ is seen. The right ventricular sinus $(R V S)$ is poorly formed and muscle bound. The pulmonary veins (RPV, LPV) are visible entering the left atrium. Fig. ${ }_{3} C$ illustrates the pulmonary artery $(P A)$ arising anteriorly from the right ventricle. It is separated from the tricuspid valve by the right margin of the conoventricular flange (RCVF). The anterior papillary muscle (APM) and ventricular septal defect (VSD) are both seen. Fig. ${ }_{3} D$ shows the abnormal origin of the aorta $(A o)$ from the left ventricle. The large conus septum $(C o S)$ separates the aorta from the pulmonary artery. It forms the roof of the anterior septal defect, and is continuous posteriorly with the left margin of the conoventricular flange ( $L C V F)$ which separates the aortic and mitral $(M V)$ valves. Note that the mitral and tricuspid valves are in fibrous continuity in the posterior margin of the defect. Note also the typical features of the morphologically left ventricle $(L V)$. 
the mitral valve entering the ventricular component and the arteries arising from the bulbar component. In relation to this $d$-loop the arteries were considered to exhibit the relation of anatomically corrected malposition $\{S, D, L\}$. An alternative description of this relation would be double outlet bulbus with 1-malposition. Associated anomalies were persistent ductus arteriosus, patent formen ovale, and single coronary artery.

\section{Case 4}

The specimen was from a male neonate dying at 2 days of age. Visceroatrial situs solitus was present and a normal spleen was observed. The cardiac apex was directed to the right and the heart was centrally positioned in the thorax (Fig. 7A). The right atrium received a right superior vena cava, a left superior vena cava via a coronary sinus, and an inferior vena cava. The chamber was blind-ending, and the only egress for right atrial blood was through a secundum atrial septal defect. A dimple was not identified in the chamber floor. The right auricle was juxtaposed to the left of the great arteries (Fig. $7 \mathrm{~A}$ and $\mathrm{B}$ ). The left atrium received 4 pulmonary veins, together with the systemic venous return via the secundum defect. It drained through a valve with morphological characteristics of a mitral valve to a main ventricular chamber (Fig. ${ }_{7} \mathrm{C}$ ). The aorta arose anteriorly from this chamber, and its posterior cusp was in tenuous fibrous continuity with the mitral valve via the central fibrous body (Fig. $7 \mathrm{C}$ ). A hypoplastic outlet chamber was situated on the right anterior shoulder of the main chamber, and a fair sized bulboventricular foramen connected the two (Fig. 7D). The aorta overrode the bulboventricular septum by approximately Io per cent. The cavity of the hypoplastic outlet chamber was barely recognizable, and the pulmonary artery arising from the chamber was atretic (Fig. 7B). The pulmonary artery arose in the same frontal plane as, and to the right of, the aorta (Fig. 7A, B). A single coronary artery arose from the right anterior aortic sinus, immediately dividing to give right and left circumflex branches. A large right anterior descending branch was present. The ductus arteriosus was patent.
The diagnosis was made of tricuspid atresia. The ventricular morphology was typical of that seen in the anomaly of single ventricle with outlet chamber, except that the right atrioventricular valve was absent. The ventricles were arranged in $d$-bulboventricular loop pattern. In relation to this loop, the arteries exhibited the relation of anatomically corrected malposition $\{\mathrm{S}, \mathrm{D}, \mathrm{L}\}$. Associated anomalies were persistent ductus arteriosus, pulmonary atresia, ventricular septal defect, persistent left superior vena cava, laevo juxtaposition of the auricles, and single coronary artery.

\section{Discussion}

\section{I) What is malposition?}

When Van Praagh and his colleagues (I97I) first introduced the concept of malposition of the two great arteries, they indicated that the term should describe all ventriculo-arterial relations which could not be considered as normal. Within this framework they then defined the special category of transposition. Great arteries were only considered to be transposed when both arose from separate morphologically inappropriate ventricles. However. having made this distinction, it now seems preferable to separate the two categories of transposed and malposed arteries, so that the term malposition itself becomes more specific (R. Van Praagh, 1974, personal communication). If the term malposition is to become fully specific, it is necessary to distinguish the malposition that occurs in double outlet situations from the malposition that is anatomically corrected. The 'double outlet' type of malposition describes the situation in which both great arteries arise from the same ventricle, be it right or left. This is distinguished from transposition because only one great artery is placed across the septum to produce a double outlet ventricle. The significance and usefulness of the malposition concept as applied

FIG. 4 Photographs to demonstrate the pertinent features of Case 2, which was associated with situs inversus totalis. Fig. $4 A$ shows the anterior view of the heart. The lungs $(R L, L L)$ are inverted. The aorta $(A o)$ arises anterior to and to the right of the pulmonary artery (not visible). Fig. $4 B$ shows the posterior aspect. The atria are inverted, so that the morphologically left atrium $(M L A)$ is right-sided and receives the pulmonary veins $(P V)$. The morphologically right atrium $(M R A)$ is left-sided and receives the systemic venous return. Fig. ${ }_{4} C$ shows the rightsided atrioventricular orifice. The morphologically left atrium drains to the morphologically left ventricle $(M L V)$ through a mitral valve $(M V)$. Note the filigreed valve of the foramen ovale (Fo). Fig. $4 D$ illustrates the abnormal origin of the right-sided aorta from the morphologically left ventricle (right-sided). Note the typical mitral valve and the fine trabeculae of the morphologically left ventricle. The aortic valve is separated from the mitral valve by the defect (VSD) but the aorta arose predominantly from the left ventricle (right-sided). The left-sided ventricle was a typical morphological right ventricle and gave rise to an atretic pulmonary artery (see Fig. 5). 


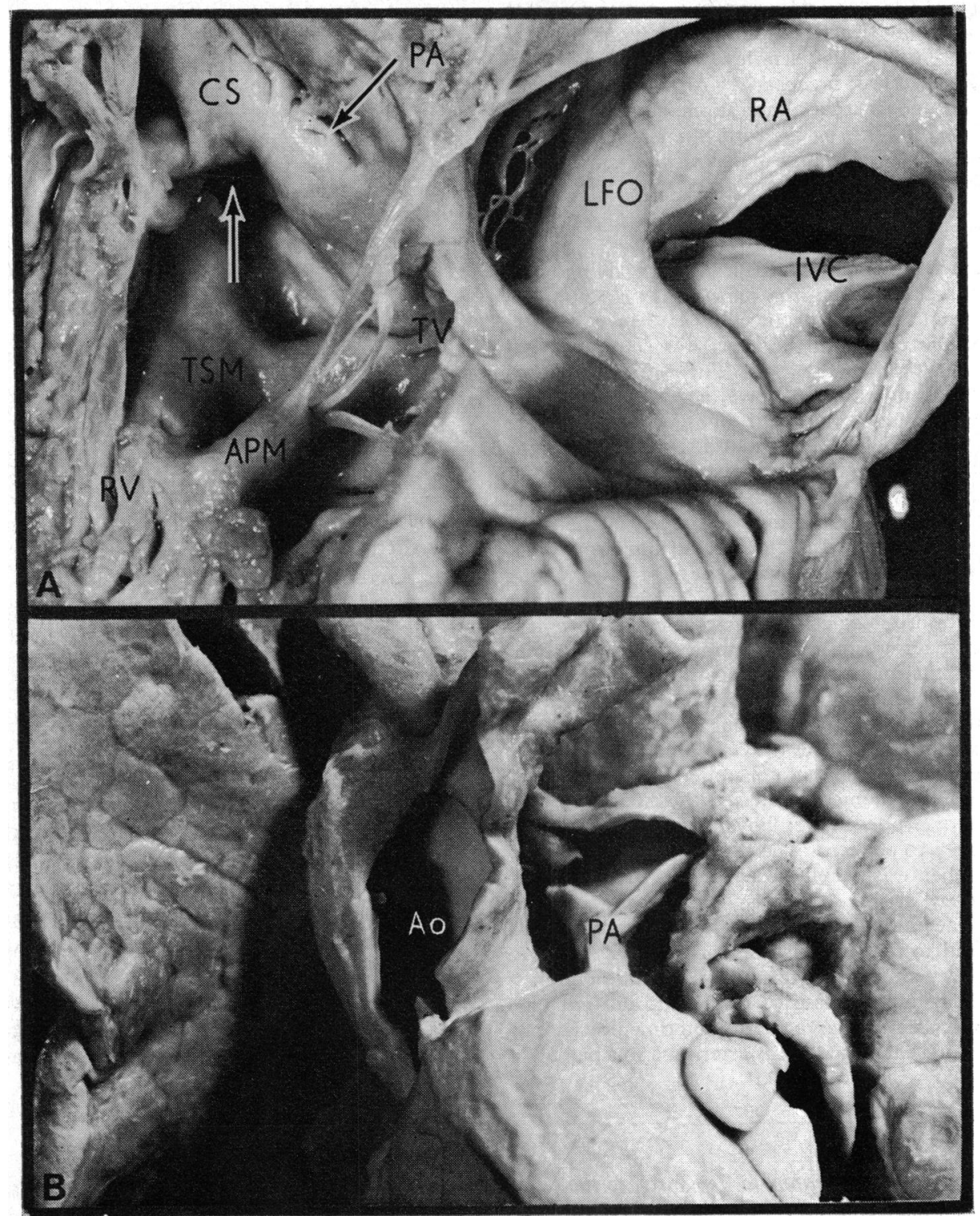

FIG. 5 Case 2. A) The left side of the heart. This is made up of the morphological right atrium $(R A)$ which opens into the morphological right ventricle $(R V)$. The opening of the inferior vena cava (IVC) and limbus fossae ovale ( $L F O)$ are both visible. The valve present is a morphologically tricuspid valve (TV) and the conspicuous anterior papillary muscle (APM) is seen arising from the trabeculum septomarginalis (TSM). The ventricular septal defect is visible above the TSM (arrow) and the prominent conus septum (CS) is seen compressing the slit-like opening of the pulmonary artery $(P A)$ which is atretic. $B)$ The orientation of the great arteries. The aorta $(A o)$ arises anteriorly, and to the right of the atretic pulmonary artery $(P A)$. The pulmonary artery branches are fed by a persistent ductus arteriosus. As illustrated in Fig. 4 and Fig. $5 A$, the aorta arises from the inverted morphological left ventricle and the atretic opening of the pulmonary artery is related to the left-sided morphological right ventricle. 
to double outlet ventricles is that it conveniently allows types of the anomalies to be distinguished in which the aorta lies either to the right or to the left of the pulmonary artery ( $d$-malposition or $l$-malposition). However, it is also necessary to distinguish double outlet malposition from the different ventriculo-arterial relation of anatomically corrected malposition.

\section{2) What is anatomically corrected malposi- tion?}

This term is used to describe the ventriculo-arterial relation in which the great arteries arise from separate ventricles, and are abnormally related to each other, but in which, despite these features, the aorta still arises from the morphologically left ventricle and the pulmonary artery arises from the morphologically right ventricle. In terms of flow, therefore, the ventricles and arteries are normally connected since right ventricular blood will be conveyed to the lungs (in the absence of other cardiac defects). For this reason Kirklin and his colleagues (1973) have termed anatomically corrected malposition a concordant ventriculo-arterial relation. Normally related great arteries are similarly concordant with their ventricles; in contrast both transpositions and double outlet situations represent discordant arterio-ventricular relations. We consider that this concept, based on both physiological and anatomical criteria, is more useful and less confusing than the concept of arterioventricular concordance and discordance recently proposed by de la Cruz et al. (1974).

Although the majority of cases of anatomically corrected malposition thus far described have possessed a subaortic conus, it is our belief that the ventriculo-arterial relation could exist in the presence of aortic-mitral continuity. It is well established that during normal development of the heart, subaortic conal musculature is absorbed to produce normal aortic-mitral continuity (Pernkopf and Wirtinger, 1933; Goor, Dische, and Lillehei, 1972; Anderson et al., 1974d). Similarly, when the pulmonary artery is transferred to the left ventricle in transposition, this can result in either presence or absence of subpulmonary conal musculature (Anderson et al., 1974c). We would, therefore, contend that continued absorption of the subaortic conus during development of anatomically corrected malposition could theoretically result in production of a malposed aorta (not normally related) in fibrous continuity with the mitral valve. We would further contend that the 'normal' position of arteries described in a case reported by Van Praagh and Van Praagh (1966) is in fact a malposition since these arteries cannot be considered as normal in position in relation to the l-loop that was present in this anomaly.

We believe that nomenclature of ventriculoarterial relations would be simplified if confined to the five categories of a) normal relations; b) transposition; c) double outlet malposition; d) anatomically corrected malposition; and e) common truncus (Table).

\section{3) How many varieties of anatomically cor- rected malposition are there?}

Since the term 'anatomically corrected malposition'. describes a ventriculo-arterial relation, it follows that anatomically corrected malposition, like transposition and double outlet ventricles, can coexist with varying anomalies of the atrioventricular segments of the heart tube. Thus, if we consider the 8 varieties of 'transposition' postulated on theoretical grounds by Geipel (1903) and by Harris and Farber (1939), in the setting of the transposition/ malposition concept, then it becomes evident that 4 of these varieties are transpositions and 4 are anatomically corrected malpositions (Fig. 8). As with transpositions, the most commonly reported variety of anatomically corrected malposition is that associated with solitus atrial chambers and atrioventricular concordance (Fig. 9A) (Raghib et al., 1966; Van Praagh and Van Praagh, 1967; Sunada et al., 1967; Kirklin et al., 1973; Freedom and Harrington, 1974; and 3 of the present cases). However, the remaining 3 varieties of anatomically corrected malposition have all now received adequate documentation. Van Praagh and Van Praagh (1967) decribed the form in which anatomically corrected malposition was associated with solitus atria and atrioventricular discordance (Fig. 9C). Anderson et al. (1972) described an example of anatomically corrected malposition with inversus atria and atrioventricular discordance (Fig. 9D). There is some controversy concerning the existence of anatomically corrected malposition in situs inversus with atrioventricular concordance (Fig. 9B). Campbell and Forgacs (1953) and Campbell and Deuchar (1965) described such cases in the material they studied at Guy's Hospital, and Shaher (1964) illustrated angiograms from one of these cases. Despite these reports, both Kirklin et al. (1973) and Van Praagh et al. (1975) considered the variety still required adequate documentation. We submit that our Case 2 provides necropsy evidence of the existence of this variety of anatomically corrected malposition. Further examples of anatomically corrected malposition can exist with the heterotaxia syndrome in which atrial situs cannot be determined. Freedom 
TABLE Ventriculo-arterial relations

\begin{tabular}{|c|c|c|}
\hline Category & Possible variations & Aortic position \\
\hline I. Normal relations & $\left\{\begin{array}{l}\text { a) With situs solitus, AV concordance } \\
\text { b) With situs solitus, AV discordance* } \\
\text { c) With situs inversus, AV concordance } \\
\text { d) With situs inversus, AV discordance* }\end{array}\right.$ & $\begin{array}{l}\text { From LV; right-sided, posterior, A-M } \\
\text { continuity } \\
\text { From LV; left-sided, posterior, A-M } \\
\text { continuity } \\
\text { From LV; left-sided, posterior, A-M } \\
\text { continuity } \\
\text { From LV; right-sided, posterior, A-M } \\
\text { continuity }\end{array}$ \\
\hline 2. Transposition & $\left\{\begin{array}{l}\text { a) With situs solitus, AV concordance } \\
\text { b) With situs solitus, AV discordance } \\
\text { c) With situs inversus, AV concordance } \\
\text { d) With situs inversus, AV discordance }\end{array}\right.$ & $\begin{array}{l}\text { From RV; anterior or posterior; right- } \\
\text { sided or left-sided; usually with conus } \\
\text { From RV; as yet only described anterior, } \\
\text { to left or right, and with conus } \\
\text { From RV; as yet only described anterior, } \\
\text { to left, and with conus } \\
\text { From RV; as yet only described anterior, } \\
\text { to right, and with conus }\end{array}$ \\
\hline $\begin{array}{l}\text { 3. Anatomically corrected } \\
\text { malposition }\end{array}$ & $\left\{\begin{array}{l}\text { a) With situs solitus, AV concordance } \\
\text { b) With situs solitus, AV discordance } \\
\text { c) With situs inversus, AV concordance } \\
\text { d) With situs inversus, AV discordance }\end{array}\right.$ & $\begin{array}{l}\text { From LV; left-sided; usually has conus } \\
\text { but could have A-M continuity } \\
\text { From LV; right-sided; usually has conus } \\
\text { but could have A-M continuity } \\
\text { From LV; right-sided; usually has conus } \\
\text { but could have A-M continuity } \\
\text { From LV; left-sided; usually has conus } \\
\text { but could have A-M continuity }\end{array}$ \\
\hline $\begin{array}{l}\text { 4a. Double outlet right } \\
\text { ventricle }\end{array}$ & $\left\{\begin{array}{l}\text { a) With situs solitus, AV concordance } \\
\text { b) With situs solitus, AV discordance } \\
\text { c) With situs inversus, AV concordance } \\
\text { d) With situs inversus, AV discordance }\end{array}\right.$ & $\begin{array}{l}\text { From RV; right-sided ( } d \text {-malposition) } \\
\text { or left-sided ( } l \text {-malposition) } \\
\text { From RV; usually } l \text {-malposition } \\
\text { From RV; usually } l \text {-malposition } \\
\text { From RV; } d \text {-malposition would be } \\
\quad \text { expected }\end{array}$ \\
\hline 4b. Double outlet left ventricle & $\left\{\begin{array}{l}\text { a) With situs solitus, AV concordance } \\
\text { Possibilities b-d have yet to be reported }\end{array}\right.$ & $\begin{array}{l}\text { From LV; } l \text {-malposition or } d \text {-malposition; } \\
\text { with or without conus }\end{array}$ \\
\hline 5. Common truncus & $\begin{array}{l}\text { Can exist with all variations of atrio- } \\
\text { ventricular relations }\end{array}$ & $\begin{array}{l}\text { Common truncus can theoretically arise } \\
\text { from right ventricle, left ventricle, or in } \\
\text { varying degrees from both ventricles; } \\
\text { origin of aorta and pulmonary arteries } \\
\text { from common truncus is also variable }\end{array}$ \\
\hline
\end{tabular}

* These anomalies have yet to be described.

Abbreviations: AV, atrioventricular; LV, left ventricle; RV, right ventricle; A-M, aortic-mitral.

FIG. 6 Photographs illustrating the pertinent morphological features of Case 3. Fig. $6 \mathrm{~A}$ shows the relation of the great arteries. The aorta $(A 0)$ arises anteriorly to and to the right of the poorly formed pulmonary artery $(P A)$. Note the single coronary artery $(S C A)$ arising from the right septal aortic sinus. Fig. $6 B$ shows the blind-ending right atrium. The atrium has been opened, and also dissected along its floor. Note that it overlies the right atrioventricular groove, and that there is no evidence of a 'dimple'. It receives the superior vena cava (SVC) and inferior vena cava (IVC) but the coronary sinus is lacking. Its only exit is via a patent foramen ovale (Fo). Fig. 6C shows the left atrium ( $L A)$ communicating with a single 'ventricular' chamber (' $S V$ ') via a morphologically mitral valve $(M V)$. The herniated floor of the fossa ovalis $(F o)$ is seen in the left atrium. Note the anterior papillary muscle of the mitral valve, and that some chordae take origin from a prominent trabecula which partially separates the ventricular chamber. Note also the pulmonary artery arising posteriorly to and to the right of the aorta. Fig. $6 D$ shows the origin of the great arteries from the anterior portion of the ventricular chamber, considered by us to be the bulbus. The aortic orifice is to the left of the stenosed pulmonary orifice, and the two are separated by the conus septum (CoS). The conoventricular flange (CVF) separates both semilunar valves from the mitral valve. Note the prominent trabecula $(T)$ which extends to the underside of the conus septum and gives some chords to the mitral valve. 


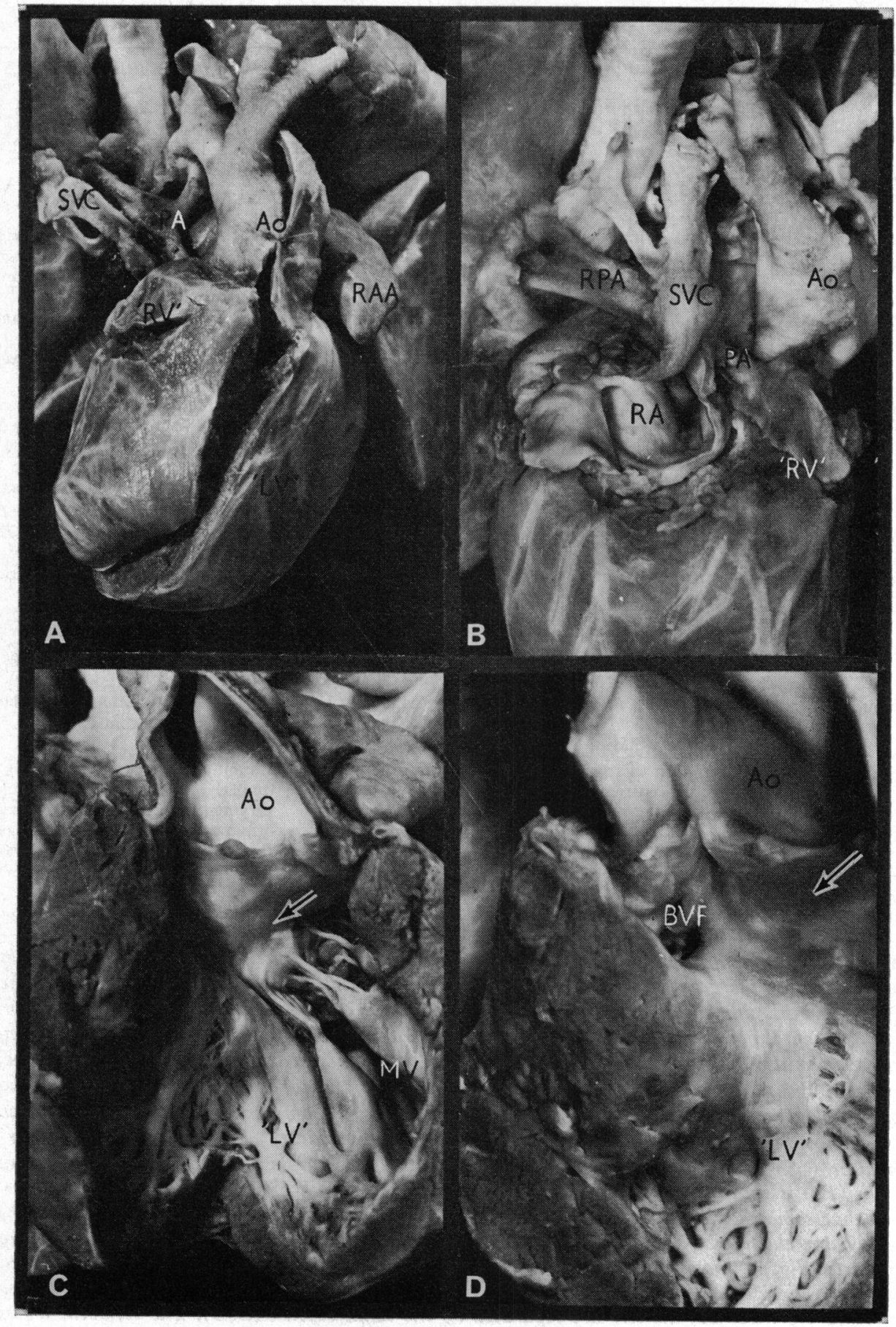




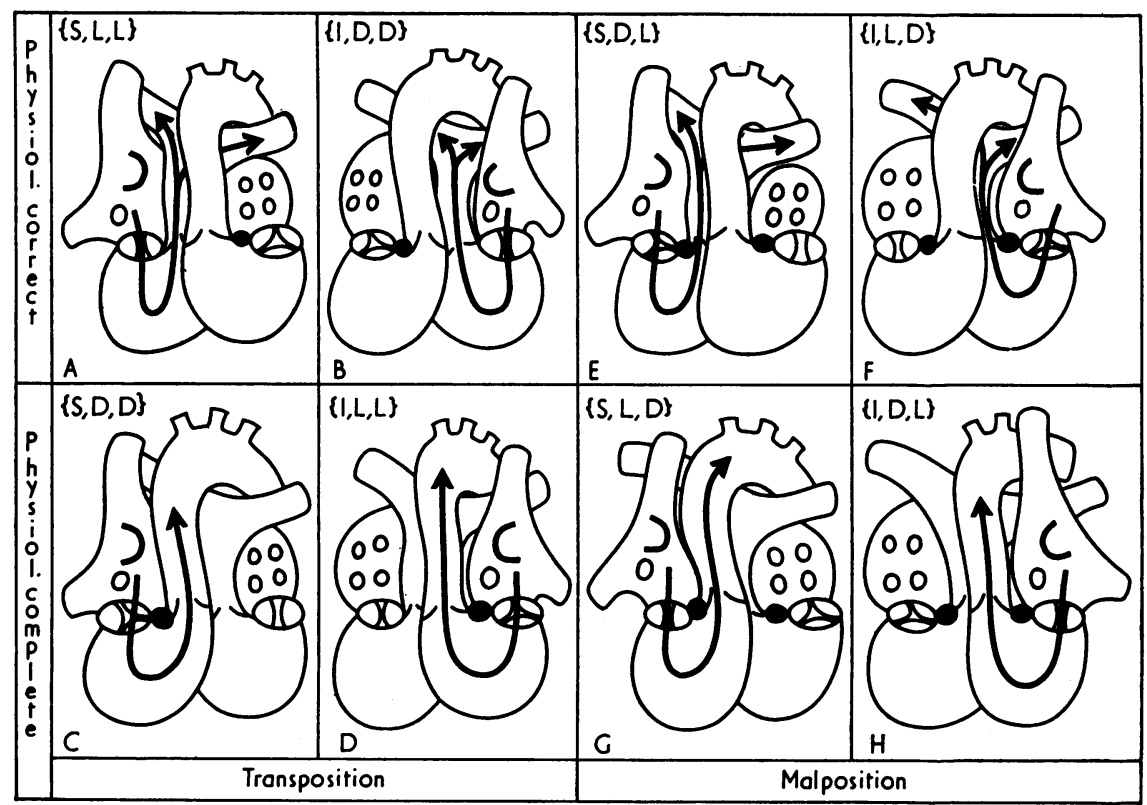

FIG. 8 Diagram illustrating how the 8 forms of 'transposition' catalogued by Geipel (1903) can be rearranged within the transposition/malposition concept of Van Praagh et al. (I97I). Note that the 8 varieties are divisible into 4 mirror-image pairs, one of each pair being associated with situs solitus $(S)$, the other with situs inversus $(I)$. Of these 4 pairs, 2 are associated with the great arteries arising from inappropriate ventricles (transposition, Fig. $8 A-D$ ). The other 2 pairs have the arteries arising unusually from appropriate ventricles (malpositions, Fig. $8 E-H$ ). The state of the circulation, being either corrected (physiol. correct) or transposed (physiol. complete), is dependent upon the presence of atrioventricular concordance or discordance. In the case of the transpositions, discordance produces physiological correction (Fig. 8A, B) and concordance produces transposition (Fig. $8 C, D$ ). In the case of the malpositions, concordance produces physiological correction (Fig. 8E, F) and discordance produces physiological transposition (Fig. 8G, H).

FIG. 7 Photographs illustrating the pertinent morphological features of Case 4. Fig. $7 A$ shows the anterior view of the heart. The aorta $(A o)$ is to the left of the pulmonary artery $(P A)$ which is atretic. The right auricle $(R A A)$ is juxtaposed to the left. The right-sided superior vena cava is seen $(S V C)$. The so-called right ventricle (' $R V$ ') is an outlet chamber situated on the right shoulder of the primitive ventricle (' $L V$ '). Fig. $7 B$ shows the blind ending right atrium $(R A)$. The origin of the pulmonary artery from the outlet chamber is demonstrated. The main pulmonary arteries (RPA - right pulmonary artery) fill via a persistent ductus arteriosus. Fig. $7 C$ demonstrates the origin of the aorta from the primitive ventricle. A mitral valve $(M V)$ drains the left atrium (not shown) and mitral-aortic valvular continuity is demonstrated (arrow). Despite this, the great arteries are abnormally related to each other and their respective ventricles, and thus malposition is present. Fig. $7 D$ shows the bulboventricular foramen (BVF) on the anterior aspect of the primitive ventricle. The outlet chamber is small and the pulmonary artery arising from it (not shown) is atretic. The mitral-aortic valvular continuity is again seen (arrow). 


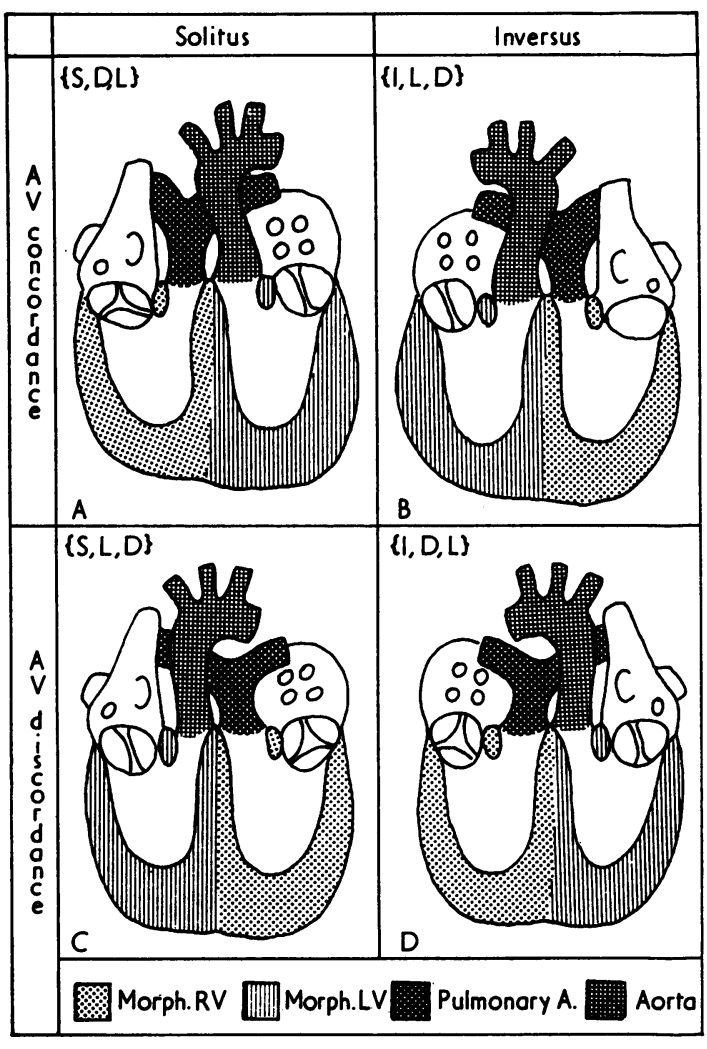

FIG. 9 Diagram illustrating the four varieties of anatomically corrected malposition (Fig. 8) in greater detail. The four varieties are composed of pairs, being associated with either solitus or inversus atrial chambers, and either $A V$ concordance or $A V$ discordance. The common feature of the 4 anomalies is the relation of the arteries to the underlying ventricles. This is 'anatomically corrected malposition', and as such can exist with varying malformations of the underlying ventricles. All 4 of these varieties have now received adequate documentation.

and Harrington (1974) described such a case in association with asplenia. Despite identification of a 'spleen' in our Case I at the original necropsy the cardiac anatomy in this specimen makes us strongly suspect that polysplenia may have been present.

\section{4) How are varieties of anatomically corrected malposition to be distinguished ?}

Since we have indicated that anatomically corrected malposition is only a description of a ventriculoarterial relation, it follows that the term does not describe the complete heart. Indeed, it is evident from the above discussion that though all 4 varieties of anatomically corrected malposition exhibit concordance of ventricles and arteries, flow through these segments would be made unphysiological by accompanying discordance between the atria and the ventricles. It is important to be able to distinguish those varieties of anatomically corrected malposition in which flow is physiologically normal from those in which flow is physiologically transposed. Similar variations in transpositions are usually distinguished by using the adjective 'complete' to describe the physiologically transposed varieties (Fig. 8C and D, $\{S, D, D\}$ and $\{I, L, L\}$ ) and 'corrected' to describe those varieties with normal flow patterns (Fig. 8A and B, $\{S, L, L\}$ and $\{I, D, D\})$. It is possible that the terms 'complete' and 'corrected' could be used to distinguish the types of anatomically corrected malposition, but confusion might be produced if the term 'corrected anatomically corrected malposition' were used. It would be preferable to discard the 'anatomically corrected' and refer simply to 'corrected malposition' to describe the varieties with normal flow patterns, and 'complete malposition' for those with transposed flow. However, this could produce further confusion with the double outlet varieties of malposition and such a nomenclature demands considerable initial knowledge. We would, therefore, suggest that the hearts be described in their full segmental arrangement (Anderson, Shinebourne, and Gerlis, 1974b). The heart illustrated in Fig. 8E would, therefore, be described as solitus atria, concordant atrioventricular relation, and anatomically corrected malposition. The nomenclature for all four varieties can then easily be shortened to the term 'concordant anatomically corrected malposition', for the two varieties with normal circulatory patterns $(\{S, D, L\}$ and $\{I, L, D\}$, Fig. $8 \mathrm{E}$ and $\mathrm{F}$ ), and the term 'discordant anatomically corrected malposition' for the two varieties with physiologically transposed circulatory patterns ( $\{S, L, D\}$ and $\{I, D, L\}$, Fig. $8 \mathrm{G}$ and $H)$. It will be noted that since anatomically corrected malposition is a concordant ventriculo-arterial relation, a discordance at atrioventricular level produces physiological transposition. In contrast, transposition of the great arteries is already an example of ventriculo-arterial discordance, therefore a second discordance at atrioventricular level serves to 'correct' the circulation.

5) Can anatomically corrected malposition coexist with single (or primitive) ventricle ?

In Cases 3 and 4 we have designated the ventriculoarterial relation as 'anatomically corrected malposi- 
tion', though right and left ventricular sinuses are not identifiable as such. Both cases have coexisting tricuspid atresia, and the association of tricuspid atresia and anatomically corrected malposition is well established (Freedom and Harrington, 1974). Thus, the apparent absence of a right ventricular sinus is not contraindicative of anatomically corrected malposition. We have recently studied 75 examples of tricuspid atresia (unpublished observations), and it is our belief that the right ventricular sinus in this anomaly is part of the so-called 'left ventricle', and that the so-called 'right ventricle' is the bulbus or outlet chamber. Tricuspid atresia is, therefore, usually a variant of 'primitive ventricle with outlet chamber'. In Case 4 presently described, the pulmonary artery arises from the bulbus, and the aorta is left-sided, arising from the primitive ventricle. Thus, though the great arteries arise from their appropriate embryological primordia, they are not normally related to these chambers. We, therefore, contend that this ventriculo- arterial relation is one of anatomically corrected malposition. In Case 3 the situation is complicated since an outlet chamber is not present. We consider the ventricular morphology to represent 'primitive ventricle without outlet chamber', and we would submit that the right side of the ventricular mass is made up of the unexpanded right ventricular sinus. We further contend that the pulmonary artery arises from the bulbus and is related to this unexpanded right ventricular sinus while the left-sided aorta is related to the left ventricular sinus, both sinuses being derived from the primitive ventricle. It is therefore our belief that, as in Case 4, the great arteries are abnormally related to their appropriate ventricular primordia and that once again the ventriculo-arterial relation is that of anatomically corrected malposition. It follows from the above discussion that we would also consider it possible to find anatomically corrected malposition in association with the anomaly of primitive (or 'single') ventricle either with or without outlet chamber

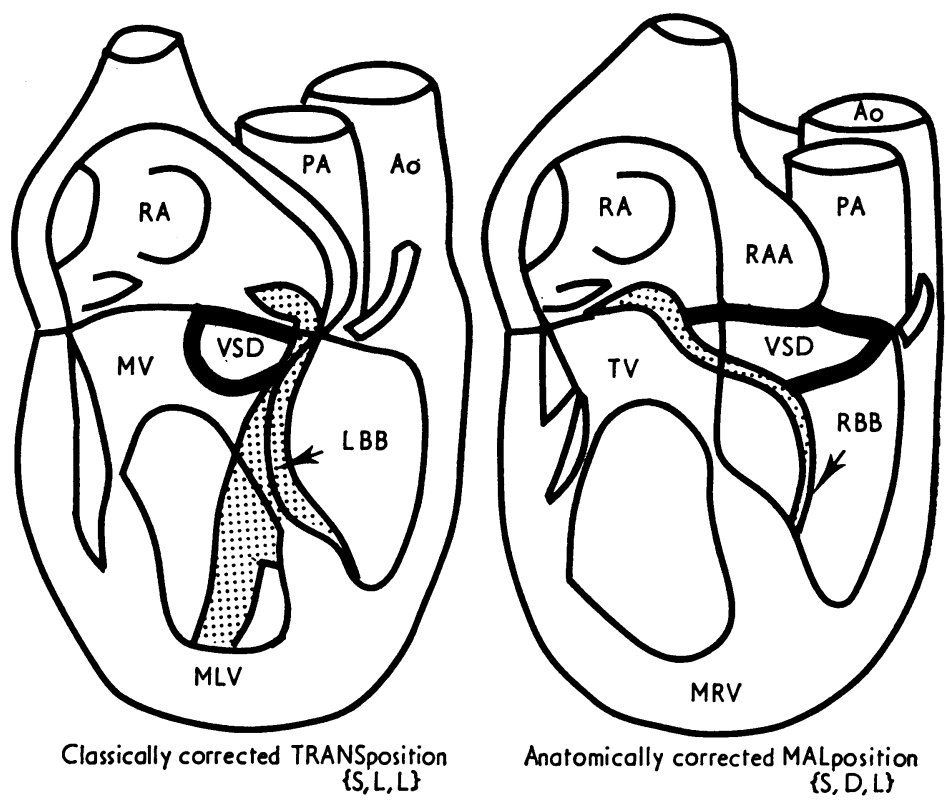

FIG. Io Diagram to compare the course of the cardiac conducting tissues in classically corrected transposition and anatomically corrected malposition. In classically corrected transposition the conducting tissue has been demonstrated to pass anterosuperiorly to accompanying septal defects, and to encircle the lateral quadrants of the pulmonary valve (Anderson et al., 1973, 1974a). In anatomically corrected malposition, in contrast, the conducting tissue is posterior to septal defects, arising from a normally situated node (Anderson et al., 1972). Note also that with solitus atrial chambers, corrected transposition is characterized by atrioventricular discordance (left ventricle (MLV) together with left bundle-branch $(L B B)$ on right), whereas corrected malposition is characterized by atrioventricular concordance (right ventricle (MRV) and right bundle-branch (RBB) on right). Other abbreviations as for Fig. 3-7. 
when both atrioventricular valves are present and empty into the primitive ventricle.

6) Is it of clinical significance to recognize anatomically corrected malposition?

Since both concordant anatomically corrected malposition and classically corrected transposition produce circulatory patterns which are potentially normal, and since both have left-sided aortae with solitus atrial chambers $(\{S, D, L\}$ and $\{S, L, L\}$, Fig. $8 \mathrm{E}$ and $\mathrm{A}$, respectively), one may wonder if it is necessary to distinguish the two conditions ? Recent findings regarding disposition of conducting tissues in the two anomalies indicate that it is vital to dis- tinguish them. In classically corrected transposition (Fig. IOA), it has been shown that the atrioventricular bundle is situated anteriorly in the septum, descends from an anterior node, and is related to the antero-superior quadrants of any accompanying ventricular septal defects (Anderson, Arnold, and Wilkinson, 1973; Anderson et al., I974a). In contrast, in anatomically corrected malposition (Fig. IOB) the bundle should be expected to occupy its more usual posterior position (Truex and Bishof, 1958). This hypothesis was supported by gross inspection of our Cases $I$ and 2, but has not been proven histologically. However, in an example of anatomically corrected malposition that was studied histologically, the bundle was observed
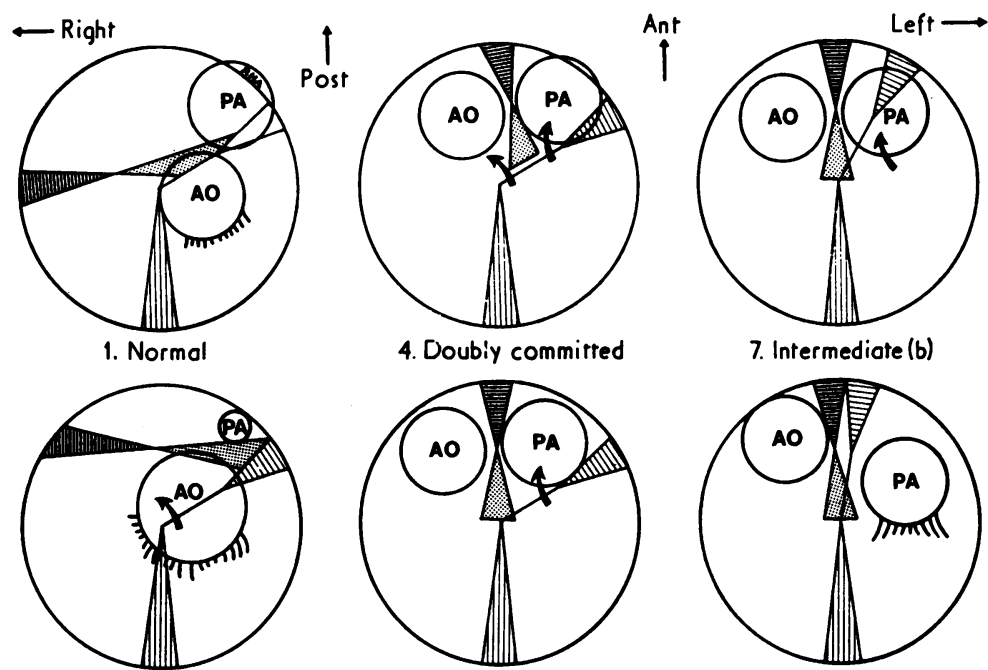

7. Intermediate (b)

2. Fallot's tetralogy
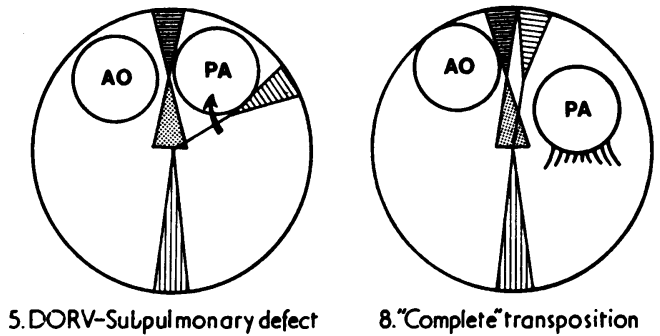

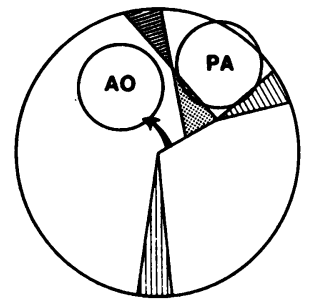

3. DORV-Suboortic defect

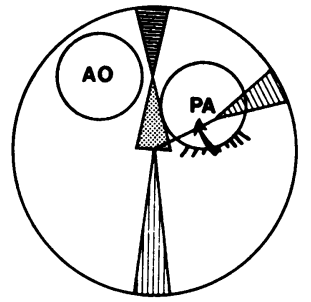

6. Intermediate (a)
8."Complete"tronsposition

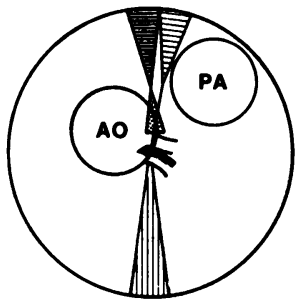

9."Posterior"transposition

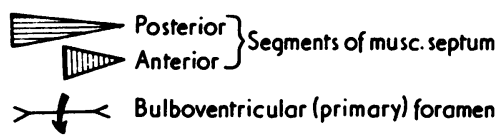

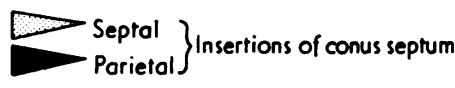

עme Atriovent-Semilunor continuity

FIG. II Diagram illustrating the spectrum of conal maldevelopment associated with solitus atrial chambers and atrioventricular concordance. The spectrum is explained on the basis of 'lack of conal inversion', 'lack of conal absorption', and realignment of the anterior ventricular septum. Reproduced with alterations from Anderson et al. (I974C). 
in a posterior position despite the presence of atrioventricular discordance (Anderson et al., 1972).

7) Is anatomically corrected malposition an embryological impossibility?

Since the ventriculo-arterial relation now described as anatomically corrected malposition was not considered to be possible embryogenetically, Van Mierop and Wiglesworth (1963) doubted the validity of the so-called examples of the anomaly previously described. Since it now seems likely that all 4 examples of anatomically corrected malposition postulated by Geipel (1903) and Harris and Farber (1939) have received adequate documentation, it is evident that the anomaly can no longer be considered an impossibility. How then is it formed? Some authors have termed the condition 'isolated bulbar inversion' (Raghib et al., 1966; Tandon and Edwards, 1974). However, consideration of the structures formed from the bulbus indicates that it is unlikely that isolated inversion of the bulbus would produce the situation of anatomically corrected malposition. Though there is doubt as to whether the right ventricular sinus is of bulbar origin (Pernkopf and Wirtinger, 1933), Streeter (1942) clearly demonstrated that the trabeculated pouch of the right ventricle developed from the bulbus. In none of the reported examples of anatomically corrected malposition was this structure inverted, as would be expected if the developmental mechanism was indeed isolated bulbar inversion. In a similar fashion, isolated ventricular inversion would not produce inversion of the trabeculated portion of the right ventricle. It would not, therefore, produce discordant anatomically corrected malposition, as is suggested by usage of the term to describe this anomaly by Kirklin et al. (1973) and Goor and Edwards (1973). Goor and Edwards (1973) and Van Praagh and Van Praagh (1967) suggested that isolated conal inversion may produce anatomically corrected malposition. This is indeed a possible mechanism, and would imply inversion of conal musculature together with the arteries. However, this inversion would be in reverse direction to that normally seen, and would occur in addition to the initial 'lack of conal inversion' shown to produce double outlet right ventricle (Goor et al., 1972; Anderson et al., 1974d). This paradox of inversion and 'lack of inversion' occurring together is possible because 'lack of inversion" can be considered as reverse inversion from the normal position. If the additional reverse inversion

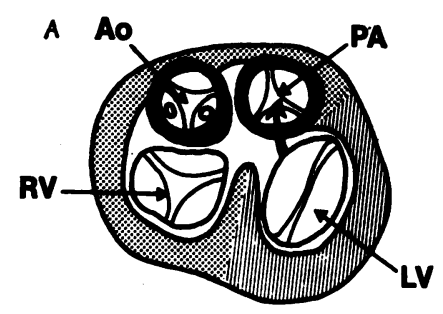

DORV with d-malposition $\{S, D, D\}$

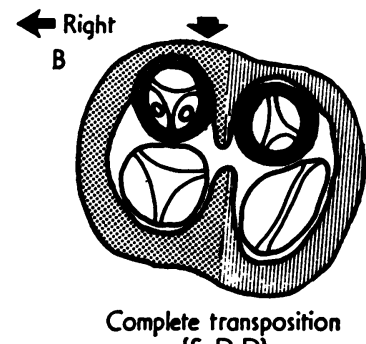

$\{S, D, D\}$

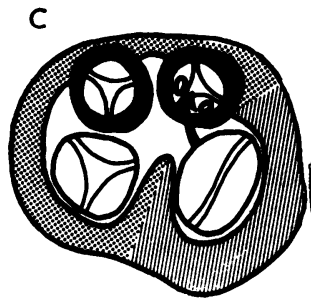

DORV with L-malposition \{S, D, L\}

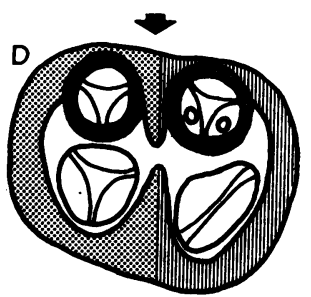

Anotomically corrected MALposition \{S, D, L\}

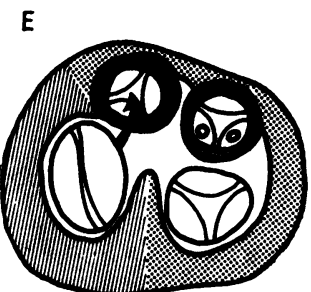

DORV.(l loop) with molposition \{S, L, L\}

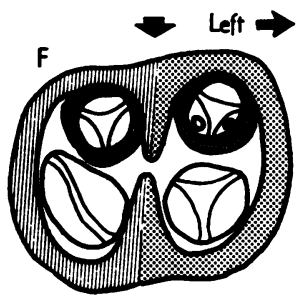

Physiologically corrected TRANSposition $\{S, L, L\}$

FIG. I2 Diagrams illustrating the mode of development of: $A$ and $B$ ) 'complete' transposition from double outlet right ventricle with $d$-malposition and subpulmonary defect; $C$ and $D$ ) anatomically corrected malposition from double outlet right ventricle with l-malposition and subaortic defect; and $E$ and $F$ ) physiologically corrected transposition from DORV with atrioventricular discordance and l-malposition. In each case, the great artery nearest to the left ventricle is taken into the ventricle by a process of conal absorption and realignment of the anterior interventricular septum. Note that the only major difference between $A$ ) and $C$ ) is reversal of the position of the aorta (see text for discussion). 
through $180^{\circ}$ did indeed occur, it might be expected to produce torsion in the great arteries, in a manner analogous to that in which normal conal inversion produces the torsion observed in normally related arteries. However, examination of specimens of anatomically corrected malposition fails to reveal such torsion. A further possibility exists to explain the morphogenesis. When considering the anomaly of double outlet right ventricle (DORV), Lincoln et al. (1975) suggested that the transition from DORV with $d$-malposition to DORV with $l$ malposition might result from 'plugging-in' of the aorta and pulmonary artery in reverse, or in other words 'isolated truncal inversion'. If this occurred in the double outlet situation, then the anomaly of anatomically corrected malposition could be produced from DORV with $l$-malposition in exactly the same way that complete transposition has been shown to be linked to DORV with $d$-malposition (Lev et al., 1972; Goor and Edwards, 1973; Anderson et al., 1974c) (Fig. II and I2). If this hypothesis is correct, then it indicates that anatomically corrected malposition could result from conal maldevelopment (Van Praagh, 1973a, b) together with truncal inversion. The latter could well be produced by formation of a 'straight septum' in reverse. It is, therefore, evident that though the 'straight septum hypothesis' (Van Mierop and Wiglesworth, 1963) can no longer be considered to produce classically complete transposition, it is possible that a variant of this mechanism may be involved in the production of anatomically corrected malposition.

We are indebted to Dr. Richard Van Praagh for his help during the preparation of this manuscript, and to Dr. J. Bliddal for bringing several of the earlier references to our attention.

\section{References}

Anderson, R. H., Arnold, R., and Jones, R. S. (1972). Dbulboventricular loop with L-transposition in situs inversus. Circulation, 46, 173.

Anderson, R. H., Arnold, R., and Wilkinson, J. L. (1973). The conducting system in congenitally corrected transposition. Lancet, I, 1286.

Anderson, R. H., Becker, A. E., Arnold, R., and Wilkinson, J. L. (1974a). The conducting tissues in congenitally corrected transposition. Circulation, 50, 911 .

Anderson, R. H., Shinebourne, E. A., and Gerlis, L. M. (1974b). Criss-cross atrioventricular relationships producing paradoxical atrioventricular concordance or discordance. Circulation, 50, 176.

Anderson, R. H., Wilkinson, J. L., Arnold, R., Becker, A. E., and Lubkiewicz, K. (I974C). Morphogenesis of bulboventricular malformations. II. Observations on malformed hearts. British Heart fournal, 36, 948.

Anderson, R. H., Wilkinson, J. L., Arnold, R., and Lubkiewicz, K. (1974d). Morphogenesis of bulboventricular malformations. I. Consideration of embryogenesis in the normal heart. British Heart fournal, 36, 242.
Campbell, M., and Deuchar, D. C. (1965). Dextrocardia and isolated levocardia. British Heart fournal, 27, 69.

Campbell, M., and Forgacs, P. (I953). Lævocardia with transposition of the abdominal viscera. British Heart Fournal, 15, 401 .

Carns, M. L., Ritchie, G., and Musser, M. J. (194I). An unusual case of congenital heart disease in a woman who lived for 44 years and 6 months. American Heart fournal, 21, 522.

de la Cruz, M. V., Amoedo, M., Rivera, F., and Attie, F. (1974). Arterioventricular relations and their classification. British Heart fournal, 36, 539.

Doerr, W. (1939). Zur Transposition der Herzchlagaden. Ein kritischer Beitrag zur Lehre der Transposition. Virchorvs Archiv für pathologische Anatomie und Physiologie und für klinische Medizin, 303, 168.

Farre, J. R. (1814). Pathological Researches, Essay I. On Malformations of the Human Heart, p. 28. Longman, Hurst, Rees, Orme, and Brown, London.

Freedom, R. M., and Harrington, D. P. (1974). Anatomically corrected malposition of the great arteries. Report of 2 cases, one with congenital asplenia; frequent association with juxtaposition of atrial appendages. British Heart Fournal, 36, 207.

Geipel, P. (1903). Weitere Beiträge zum Situs transverus und zur Lehre von den Transpositionen des grossen Gefässe der Herzens. Archiv für Kinderheilkunde, 35, II2.

Goor, D. A., Dische, R., and Lillehei, C. W. (1972). The conotruncus. I. Its normal inversion and conus absorption. Circulation, 46, 375.

Goor, D. A., and Edwards, J. E. (1973). The spectrum of transposition of the great arteries: with specific reference to developmental anatomy of the conus. Circulation, 48, 406.

Harris, J. S., and Farber, S. (1939). Transposition of the great cardiac vessels (with special reference to the phylogenetic theory of Spitzer). Archives of Pathology, 28, 427.

Kirklin, J. W., Pacifico, A. D., Bargeron, L. M., and Soto, B. (1973). Cardiac repair in anatomically corrected malposition of the great arteries. Circulation, 48, 153.

Lev, M., Bharati, S., Meng, C. C. L., Liberthson, R. R., Paul, M. H., and Idriss, F. (1972). A concept of double outlet right ventricle. Fournal of Thoracic and Cardiovascular Surgery, 64, 271.

Lev, M., and Rowlatt, U. F. (196r). The pathologic anatomy of mixed levocardia. American fournal of Cardiology, 8, 216.

Lewis, F. T., and Abbott, M. E. (1915). Reversed torsion of the human heart. Anatomical Record, 9, 103.

Lincoln, C., Anderson, R. H., Shinebourne, E. A., English, T. A. E., and Wilkinson, J. L. (1975). Double outlet right ventricle with l-malposition of the aorta. British Heart Journal, 37, 453 .

Pernkopf, E., and Wirtinger, Q. (1933). Die transposition der Herzostien -ein Versuch der Erklärung dieser Erscheinung. Zeitschrift für Anatomie und Entwicklungsgeschichte, 100, 563.

Raghib, G., Anderson, R. C., and Edwards, J. E. (1966). Isolated bulbar inversion in corrected transposition. American fournal of Cardiology, 17, 407.

Rokitansky, K. F. von (1875). Die Defecte der Scheidewände des Herzens, p. 27. Braumüller, Vienna.

Shaher, R. M. (1964). Complete and inverted transposition of the great vessels. British Heart fournal, 26, 51 .

Streeter, G. L. (1942). Developmental horizons in human embryos. Contributions to Embryology, 30, $21 \mathrm{r}$.

Sunada, T., Teramoto, S., Nakanishi, M., Fujiwara, T., and Senno, Y. (1967). Corrected transposition of the great vessels: a case of Cardell BI type. Fapanese fournal of Thoracic Surgery, 20, 389. 
Tandon, R., and Edwards, J. E. (1974). Tricuspid atresia. Fournal of Thoracic and Cardiovascular Surgery, 67, 530.

Truex, R. C., and Bishof, J. K. (1958). Conduction system in human hearts with interventricular septal defects. fournal of Thoracic Surgery, 35, 421.

Van Mierop, L. H. S., and Wiglesworth, F. W. (1963). Pathogenesis of transposition complexes. II. Anomalies due to faulty transfer of the posterior great artery. American fournal of Cardiology, 12, 226.

Van Praagh, R. (1973a). Conotruncal malformations. In Heart Disease in Infancy, p. 141. Ed. by B. G. Barratt-Boyes, J. M. Neutze, and E. A. Harris. Churchill Livingstone, Edinburgh and London.

Van Praagh, R. (1973b). Do side by side arteries merit a special name? American fournal of Cardiology, 32, 874 .

Van Praagh, R., Durnin, R. E., Jockin, H., Wagner, H. R., Korns, M., Garabedian, H., Ando, M., and Calder, A. L. (1975). Anatomically corrected malposition of the great arteries (S,D,L). Circulation, 5I, 20.
Van Praagh, R., Perez-Trevino, C., Lopez-Cuellar, M., Baker, F. W., Zuberbuhler, J. R., Quero, M., Perez, V. M., Moreno, F., and Van Praagh, S. (197I). Transposition of the great arteries with posterior aorta, anterior pulmonary artery, subpulmonary conus, and fibrous continuity between aortic and atrio-ventricular valves. American fournal of Cardiology, 28, 621.

Van Praagh, R., and Van Praagh, S. (1966). Isolated ventricular inversion: a consideration of morphogenesis, definition and diagnosis of non-transposed and transposed great arteries. American fournal of Cardiology, 17, 395.

Van Praagh, R., and Van Praagh, S. (1967). Anatomically corrected transposition of the great arteries. British Heart fournal, 29, II2.

Requests for reprints to Dr. R. H. Anderson, Department of Paediatrics, Cardiothoracic Institute, Brompton Hospital, Fulham Road, London SW3 6HP. 